\title{
Büyük Hadron Çarpıştırıcısı'nda yüksek halka katkılı Standart Model Higgs sektörü
}

\author{
Yaşar HİÇYILMAZ* \\ ${ }^{1}$ Balıkesir Üniversitesi Fen-Edebiyat Fakültesi Fizik Bölümü, Çă̆ış kampüsü, Balıkesir. \\ Gelis Tarihi (Received Date): 12.04 .2019 \\ Kabul Tarihi (Accepted Date): 07.08.2019
}

\section{Özet}

Bu çalışmada, Büyük Hadron Çarpıştırıcısı'nda (BHÇ) Standart Model'in Higgs sektörü yüksek halka mertebelerinde incelenmiştir. Literatürde dört halka mertebesine kadar hesaplanmış olan Higgs'in efektif potansiyelinden türetilecek Higgs'in öz bağlaşım sabitleri kullanılarak BHÇ’daki Higgs süreçlerine ait tesir kesitleri hesaplanmıştır. Bu sayede Standart Model öngörüsü çerçevesindeki Higgs sektörü, yüksek halka mertebelerinde düzeltilmiş haliyle çarpıştırıcılarda test edilebilecek ve çıkan sonuçlar elimizde bir altyapı olduğu için sağlıklı bir şekilde tartışılabilecektir.

Anahtar kelimeler: Standart model, Higgs sektörü, büyük hadron çarpıştırıcısı.

\section{Standard Model Higgs sector with high loop contributions at Large Hadron Collider}

\begin{abstract}
In this study, we investigate the Standard Model Higgs sector at high loop levels at Large Hadron Collider (LHC). To analyze Higgs process without background pollution, cross sections that belong to the Higgs process has been calculated by using self coupling constants of Higgs boson produced by effective potential of Higgs boson which is calculated up to four loop levels as known in literature. It is possible to observe this Higgs process at LHC collisions. Thus, Higgs sector bordered by the predictions of the SM can be tested at colliders with corrected form on high loop levels and the results can be discussed properly since we have groundwork.
\end{abstract}

Keywords: Standard model, Higgs sector, large hadron collider.

\footnotetext{
*Yaşar HİÇYILMAZ, yasarhicyilmaz@balikesir.edu.tr, http://orcid.org/0000-0002-3222-7942
} 


\section{Giriş}

Büyük Hadron Çarpıştırıcısı'nda Higgs bozonunun keşfiyle başlayan süreç sonucunda yüksek enerji fiziği açısından oldukça heyecan verici ve bir o kadar da ilginç bir durum ile karşı karşıyayız. Bir yandan, keşfedilen skaler bozon Standart Model (SM) öngörüleri ile tutarlı görünüyor iken, diğer yandan ise karanlık madde, karanlık enerji ve daha birçok fiziksel olgunun doğası ve kökenleri üzerine Standart Model'in ötesinde yeni fizik senaryolarına olan ihtiyacımız halen yerinde durmaktadır. Öte yandan SM'in kurgusu içerisinde kütle çekimini barındırmadığı sürece efektif bir teoriden öteye gidemediği de bir gerçektir.

Son yıllara kadar elimizde çok zengin teorik modellerin mevcudiyeti ve tahminleri ile birlikte deneysel verilerin eksikliği göze çarpıyordu. Özellikle Büyük Hadron Çarpıştırıcısı (BHÇ) ölçümleri ile deneysel verilerin ortaya çıkması sayesinde en popüler yeni fizik senaryoları olarak değerlendirilebilecek modeller olan süpersimetrik modellerin Higgs sektörüne dönük detaylı öngörülerinin deneysel ölçümlerle yüzleşme sürecinde ölüm kalım savaşı vermeleri kaçınılmazdır. Bu savaş hem özelde süpersimetri hemde iki Higgs dublet modeli (THDM) gibi genelde farklı Higgs mekanizmaları barındıran tüm yeni fizik adayları için geçerlidir. Deneysel olarak gözlemlenmiş olan skaler bozon Standart Model Higgs bozonunun tüm özellikleri ile uyumlu görünmektedir ve SM'nin öngördüğü kütle aralığında gözlemlenmiş olarak değerlendirilebilir. Özetle, deneysel sonuçlar Standart Model'i tamamlamış gibi görünmekte ama henüz bizlere beklediğimiz yeni fizik senaryolarına dönük ne süpersimetri ne de başka bir SM ötesi bir senaryo hakkında ipucu vermemektedir.

Elbette bu durum deneysel verilerin zenginleşmesi ve hassasiyetlerinin artması sonucunda değişebilir. Bu sebeplerden dolayı, artık Standart Model Higgs'i olarak tanımlanan parçacığın özelliklerinin araştırılması, Standart Model'deki elekrozayıf simetri kırınımının tam olarak anlaşılması ya da SM ötesi yeni teoriler kurma açısından da büyük öneme sahiptir.

Büyük Hadron Çarpıştırıcısı'nda (BHÇ) Higgs bozonuna dönük ölçülmesi gereken en önemli özelliklerinden birisi kendisi ile bağlaşımıdır. Özellikle Higgs'in kendisi ile üçlü bağlaşımı Higgs potansiyelinin tam olarak anlaşılması için hayati öneme sahiptir. Çarpıştırıcı süreci bağlamında baktığımızda üçlü Higgs özbağlaşımını ölçebileceğimiz süreçlerin adı çift Higgs üretimidir [1-6]. Diğer yandan Higgs'in diğer bir özbağlaşımı olan dörtlü Higgs bağlaşımı, dahil olduğu üçlü Higgs üretim süreçlerinin şu an ki ya da gelecek çarpıştırıcılardaki deneylerde gözlemlenmesinin zorluğu bakımından düşük kesinlikle bile ölçülmesi maalesef çok zordur [7]. Bu çalışmada üzerinde duracağımız süreçler daha yakın bir zamanda sonuç alınabilecek olan çift Higgs üretimi süreçleridir.

Standart Model Higgs sektörünü temel seviyede ele almak oldukça basittir. Bilindiği gibi en basit bozunum diyagramı olan ağaç mertebesinde hesaplanan Higgs bozonu bağlaşım sabitlerinde bile daha üst mertebe halkalar göz önüne alındığında, teoriden gelen bir belirsizlik vardır. Bu yüzden Higgs potansiyeline eklenecek her bir halka katkısı teoriden gelecek belirsizliği azaltacağından dolayı önemlidir ve göz önüne alınmalıdır. Teorik olarak SM'de ağaç mertebesinde ve halka mertebelerinde Higgs'in efektif potansiyeli farklı olduğundan, kendisi ile bağlaşım sabitleri de farklı olacaktır. $\mathrm{Bu}$ farkın bilinmesi ve Higgs'in kendisi ile bağlaşım sabitlerinin daha net ortaya 
çıkarılması ile deneylerde bulunacak olası sonuçların Standart Model'i mi doğruladığı yoksa Standart Model ötesi yeni fiziğe mi kapı açtı̆̆ının anlaşılabilecektir.

$\mathrm{Bu}$ nedenlerden dolayı, SM Higgs sektöründeki teorik belirsizliğin azaltılması ve BHÇ’de test edilmesi bu çalışmanın temel motivasyonunu oluşturmaktadır. Çalışmanın ikinci bölümünde genel olarak Standart Model'in Higgs Mekanizması'nın yapısına değinilecek ve kullandığımız halka düzeltmeleri verilecektir. Üçüncü kısımda BHÇ'de Higgs çifti üretim süreçlerinden bahsedilecektir. Dördüncü kısımda halka katkılı Higgs özbağlaşımlarından ve izlediğimiz yöntem bahsedilecektir. Son bölümde ise yapılan analizler ve alınan sonuçlar grafikler ve tablolar halinde gösterilecek ve elde edilen sonuçlar tartışılacaktır.

\section{Standart Model Higgs sektörü ve halka katkıları}

Elektrozayıf teori fermiyon-fermiyon ve fermiyon-ayar bozonu arasındaki etkileşimleri doğru bir şekilde tahmin etmesine karşın, kütleli oldukları deneylerce kanıtlanan fermiyonlar, $\mathrm{W}$ ve $\mathrm{Z}$ bozonlarının nasıl kütle kazandıklarına dair herhangi bir açıklama getirememektedir. Böyle kütle terimlerinin Lagrangiana elle eklenmesi hem lokal ayar değişmezliğini bir müdahale ile kırar hem de fiziksel açıklamadan yoksundur. BroutEnglert-Higgs mekanizmas1 [8-11] bu problemi, Elektrozayıf SU(2)xU(1) simetrisinin kendiliğinden kırılmasını sağlayacak

$V(\phi)=\mu^{2}\left(\phi^{\dagger} \phi\right)+\lambda\left(\phi^{\dagger} \phi\right)^{2}$

potansiyelini Standart Model Lagrangian'ina ekleyerek çözmektedir. Burada $\phi$, Higgs alanı olarak adlandırılan bir çiftli kompleks skaler alandır. Öte yandan ekstra skaler alan için eklenen toplam Lagrangian terimi

$L_{\text {skaler }}=\left(D^{\mu} \phi\right)^{\dagger}\left(D_{\mu} \phi\right)-V(\phi)$

şeklindedir.

$\mu^{2}<0$ durumu için, (2)'deki Lagrangian $\phi$ alanı için simetrik kalmasına rağmen, bu Lagrangian'ın gerektirdiği vakum, küçük pertürbasyonlar için simetrik değildir. Dolayısıyla simetri kendiliğinden kırılmıştır ve bu duruma "Kendiliğinden Simetri Kırılması" denir. Ayrıca teoriye kütleli olan yeni bir skaler bir parçacık eklenmiştir. Burada olan şey tam olarak global ayar simetrisinin kırılması sonucu ortaya çıkan Goldstone bozonunun kendiliğinden kırılan lokal ayar simetrisi ile bir vektör bozon tarafindan yutularak bu bozona yeni bir serbestlik derecesi başka bir deyişle kütle kazandırmasıdır. Kısacası Elektrozayıf simetrinin kendiliğinden kırılması sonucu $\mathrm{W}$ ve $\mathrm{Z}$ bozonları kütle kazanır. Öte yandan elektromanyetik simetri kırılmadan kaldığından dolayı foton kütlesiz kalmıştır. 
Kütle kazanan ayar bozonlarının kütleleri

$m_{W^{+}}=m_{W^{-}}=\frac{1}{2} v g$
$m_{Z}=\frac{1}{2} v \sqrt{\left(g^{2}+g^{\prime 2}\right)}$

şeklindedir. Burada $v$, vakum beklenen değerini g ve g' ise elektromanyetik ve zayıf etkileşimin ayar kuplajını ifade eder. Fermiyonlar ise Higgs alanı ile etkileşimi sonucu kütle kazanırlar. Yukawa etkileşimleri adı verilen bu etkileşimler için Lagrangian terimi

$$
L_{\text {Yukawa }}=-y_{i j}\left[\bar{\psi}_{i}^{L} \phi \psi_{j}^{R}+\bar{\psi}_{i}^{R} \phi \psi_{j}^{L}\right]
$$

Vakum etrafında açılmış Higgs potansiyelinin en basit hali

$$
V(h)=\frac{1}{2}\left(\partial_{\mu} h\right)^{2}-\left(\lambda v^{2}\right) h^{2}-\lambda v h^{3}-\frac{1}{4} \lambda h^{4}
$$

Şeklinde olup bu potansiyel "Ağaç seviyesinde Higgs potansiyeli” olarak adlandırılır. Burada h, vakum etrafinda salınım yapan Higgs alanını temsil eder. Higgs bozonunun kendisi ile etkileşiminden elde edilecek kütle terimi ise (5) eşitliğinden elde edilir.

$m_{h}=\sqrt{2 \lambda v^{2}}$

Yukarıda bahsedilen model elektrozayıf simetriyi kırmak için çok sezgisel bir yol olmasına karşın yumuşak bir simetri kırılması için tek yol değildir. Daha önce anlatılanlardan da anlaşılacağı gibi simetrinin kendiliğinden kırılmasına yol açan, Lagrangiana yeni bir skaler alan (Higgs alanı) ve bu alana ait içerisinde kompleks bir kütle terimi $\left(\mu^{2}<0\right)$ bulunan, (1) eşitliğinde gösterilen bir $\mathrm{V}(\phi)$ potansiyeli eklemektir. Öte yandan Coleman ve Weinberg böyle kompleks bir kütle teriminin yokluğunda bile efektif ağaç seviyesi potansiyeline halka etkileşimlerinden gelen kuantum düzeltmelerinden dolayı simetrinin kendiliğinden kırılabileceğini göstermişlerdir [12].

Coleman ve Weinberg $(\mathrm{CW})$ 'in analizi giren ve çıkan parçacığın sadece teorideki skaler $\phi$ olduğu tüm diyagramların bulunduğu efektif bir potansiyel hesaplamayı içermektedir. Başka bir deyişle ağaç seviyesi üzerinde ki kuantum etkilerinin de potansiyele dahil edilmesidir. CW'nin orijinal çalışmasında bir halka düzeyinde efektif potansiyelin analizi yapılmıştır. Bu analize göre 1-halka mertebesinde efektif potansiyelin tamamı

$$
V=\frac{\lambda}{4 !} \phi^{4}+\frac{\lambda^{2} \phi^{4}}{256 \pi^{2}}\left(\ln \frac{\phi^{2}}{M}-\frac{25}{6}\right)
$$

şeklindedir.

Higgs'in halka katkılarından gelen düzeltmeler eklenmiş efektif potansiyel yardımıyla Standart Model Higgs sektöründeki teorik belirsizlik azaltılmış olur. Literatürde iki halka katkısına kadar hesaplanmış efektif Higgs potansiyeli $[13,14]$ bulunmaktadır. Bu 
çalışmada kullanılan üç ve dört halka mertebesinde Higgs'in efektif potansiyeli $[15,16]$ makalesinde hesaplanmıştır. Buna göre Standart Model Elektrozayıf sektörü için ağaç düzeyinde Higgs potansiyeli ve birinci, ikinci, üçüncü ve dördüncü halka seviyelerinde top kuark için bu potansiyele gelecek olan düzeltmeler sırasıyla

$$
\begin{aligned}
& \mathrm{V}^{(1)}=-\mathrm{N}_{\mathrm{c}} \mathrm{T}^{2}[\overline{\ln }(T)-3 / 2] \\
& \mathrm{V}^{(2)}=\mathrm{g}_{3}^{2} \mathrm{~N}_{\mathrm{c}} \mathrm{C}_{\mathrm{F}} \mathrm{T}^{2}\left[6 \overline{\ln }^{2}(\mathrm{~T})-16 \overline{\ln }(\mathrm{T})+18\right] \\
& +\mathrm{y}_{t}^{2} \mathrm{~N}_{\mathrm{c}} \mathrm{T}^{2}\left[-\frac{3}{2} \overline{\ln }^{2}(\mathrm{~T})+8 \overline{\ln }(\mathrm{T})-\frac{23}{2}-\frac{\pi^{2}}{6}\right] \\
& \mathrm{V}^{(3)}=\mathrm{g}_{3}^{4} \mathrm{~N}_{\mathrm{c}} \mathrm{C}_{\mathrm{F}} \mathrm{T}^{2}\left\{\mathrm { C } _ { \mathrm { G } } \left[-\frac{22}{3} \overline{\ln }^{3}(\mathrm{~T})+\frac{185}{3} \overline{\ln }^{2}(\mathrm{~T})\right.\right. \\
& +\left(24 \zeta(3)-\frac{1111}{6}\right) \overline{\ln }(\mathrm{T})+\frac{2609}{12}+\frac{44}{45} \pi^{4} \\
& \left.-\frac{232}{3} \zeta(3)+\frac{16}{3} \ln ^{2}(2)\left[\pi^{2}-\ln ^{2}(2)\right]-128 \operatorname{Li}_{4}(1 / 2)\right] \\
& +\mathrm{C}_{\mathrm{F}}\left[-24 \overline{\ln }^{3}(\mathrm{~T})+63 \overline{\ln }^{2}(\mathrm{~T})-(48 \zeta(3)\right. \\
& \left.+\frac{121}{2}\right) \overline{\ln }(\mathrm{T})+\frac{85}{12}-\frac{88}{45} \pi^{4}+192 \zeta(3) \\
& \left.-\frac{32}{3} \ln ^{2}(2)\left[\pi^{2}-\ln ^{2}(2)\right]+256 \operatorname{Li}_{4}(1 / 2)\right] \\
& +\mathrm{T}_{\mathrm{F}}\left[48 \overline{\ln }(\mathrm{T})-\frac{232}{3}+96 \zeta(3)\right] \\
& +\mathrm{T}_{F} \mathrm{~N}_{\mathrm{q}}\left[\frac{8}{3} \overline{\ln }^{3}(\mathrm{~T})-\frac{52}{3} \overline{\ln }^{2}(\mathrm{~T})+\frac{142}{3} \overline{\ln }(\mathrm{T})\right. \\
& \left.\left.-\frac{161}{3}-\frac{64}{3} \zeta(3)\right]\right\}+\mathrm{g}_{3}^{2} y_{t}^{2} \mathrm{~N}_{\mathrm{c}} \mathrm{C}_{\mathrm{F}} \mathrm{T}^{2}\left\{15 \overline{\ln }^{3}(\mathrm{~T})-90 \overline{\ln }^{2}(\mathrm{~T})\right. \\
& +\left[407 / 2+3 \pi^{2}+60 \zeta(3)\right] \overline{\ln }(\mathrm{T})-54 \zeta(3) \\
& -\frac{2393}{12}-\frac{29}{6} \pi^{2}+\frac{31}{15} \pi^{4}+\frac{32}{3} \ln ^{2}(2)\left[\pi^{2}-\ln ^{2}(2)\right] \\
& \left.-256 \mathrm{Li}_{4}(1 / 2)\right\}+y_{t}^{4} \mathrm{~N}_{\mathrm{c}} \mathrm{T}^{2}\left\{-\frac{9}{4} \overline{\ln }^{3}(\mathrm{~T})+\frac{57}{4} \overline{\ln }^{2}(\mathrm{~T})\right. \\
& +\left[-\frac{3}{4} \pi^{2}-\frac{121}{4}-12 \zeta(3)\right] \overline{\ln }(\mathrm{T})+\frac{529}{24}+\frac{23}{12} \pi^{2} \\
& -\frac{22}{45} \pi^{4}+\frac{93}{2} \zeta(3)-\frac{8}{3} \ln ^{2}(2)\left[\pi^{2}-\ln ^{2}(2)\right] \\
& \left.+64 \mathrm{Li}_{4}(1 / 2)\right\}+y_{t}^{4} \mathrm{~N}_{c}^{2} \mathrm{~T}^{2}\left\{\frac{7}{2} \overline{\ln }^{3}(\mathrm{~T})+\frac{17}{4} \overline{\ln }^{2}(\mathrm{~T})\right. \\
& \left.+\left[-\frac{659}{8}-\frac{5}{6} \pi^{2}\right] \overline{\ln }(\mathrm{T})+\frac{4903}{48}+\frac{3}{4} \pi^{2}-64 \zeta(3)\right\}
\end{aligned}
$$




$$
\begin{aligned}
\mathrm{V}^{(4)} & =\mathrm{g}_{3}^{6} \mathrm{~T}^{2}\left\{\frac{13820381}{270}+\frac{1747112}{45} \zeta(3)+\frac{1984}{9} \zeta(5)\right. \\
& -\frac{40288}{9} \zeta^{2}(3)-\frac{298894}{1215} \pi^{4}-\frac{1780}{243} \pi^{6}+\frac{5888}{135} \ln ^{5}(2) \\
& -\frac{5888}{88} \pi^{2} \ln ^{3}(2)-\frac{36064}{405} \pi^{4} \ln (2)+\frac{78464}{81} \ln ^{2}(2)\left[\ln ^{2}(2)-\pi^{2}\right] \\
& +\frac{627712}{27} \mathrm{Li}_{4}(1 / 2)-\frac{47104}{9} \mathrm{Li}_{5}(1 / 2)+\overline{\ln }(\mathrm{T})\left(\frac{27680}{3} \zeta(3)\right. \\
& -\frac{63200}{9} \zeta(5)-\frac{1547146}{27}-\frac{208}{9} \pi^{4}+\frac{640}{3} \ln ^{2}(2)\left[\ln ^{2}(2)-\pi^{2}\right] \\
& \left.-5120 \mathrm{Li}_{4}(1 / 2)\right)+(30584-2400 \zeta(3)) \overline{\ln }^{2}(\mathrm{~T}) \\
& \left.-9144 \overline{\ln }^{3}(\mathrm{~T})+1380 \overline{\ln }^{4}(\mathrm{~T})\right\}
\end{aligned}
$$

şeklindedir. Burada $C_{G} \mathrm{SU}(3)$ ayar grubunun Casimir invaryant1, $C_{F}, T_{F}$ ve $N_{C}$ ise sırası ile Casimir invaryant, temel gösterimin boyutu ve teorideki kuarkların sayısıdır. $\mathrm{T}$, üst kuark kütle karesini ifade eder. Diğer yandan, $\zeta(\mathrm{x})$ ve $\mathrm{Li}_{4}(\mathrm{x}), \mathrm{Li}_{5}(\mathrm{x})$ sirasiyla Riemann zeta fonksiyonu ve Logaritmik integral serisi olup,

$$
\overline{\ln }(\mathrm{X}) \equiv \ln \left(\mathrm{X} / \mathrm{Q}^{2}\right)
$$

şeklindedir.

Kuantum halka düzeltmelerine bakıldığında, içerisinde logaritmik ifadelerin bulunduğu görülür. Logaritmik ifadelerin açılması ile dört halka seviyesinde Higgs efektif potansiyelinin yapısı Higgs alanı, h'nin kuvvetleri cinsinden

$$
\begin{aligned}
V_{\text {eff }}(h) & =V^{0}+A^{0}+\left(V_{h}^{0}+A_{h}\right) h+\left(V_{h^{2}}^{0}+A_{h^{2}}\right) h^{2} \\
& +\left(V_{h^{3}}^{0}+A_{h^{3}}\right) h^{3}+\left(V_{h^{4}}^{0}+A_{h^{4}}\right) h^{4}+A_{h^{5}} h^{5}+A_{h^{6}} h^{6}+O\left[h^{7}\right]
\end{aligned}
$$

şeklindedir.

Burada $V_{i}^{0}$ terimleri efektif potansiyele ağaç mertebesinden gelen terimleri, $A_{j}$ ise logaritmik terimleri seri olarak açılmış halka etkilerinden gelen terimleri ifade eder $\left(i=\mathrm{h}, \mathrm{h}^{2}, \mathrm{~h}^{3}, \mathrm{~h}^{4}\right.$ ve $\left.\mathrm{j}=\mathrm{h}, \mathrm{h}^{2}, \mathrm{~h}^{3}, \mathrm{~h}^{4}, \mathrm{~h}^{5}, \mathrm{~h}^{6}\right)$. Dolayısıyla (5) eşitliğinde ağaç seviyesinde Higgs bozonunun kendisi ile sadece üçlü ve dörtlü bağlaşımı bulunurken, halka seviyelerinde logaritmik terimlerin açılması ile daha çok Higgs'in kendisi ile bağlaştığı beşli ve altılı Higgs özbağlaşımlarının bulunduğu durumlar mümkün olabilir. 


\section{Büyük Hadron Çarpıştırıcısı'nda Higgs çifti üretimi}

2012 yılının Temmuz ayında Büyük hadron çarpıştırıcısında yapılan iki farklı deneyden ATLAS ve CMS'in araştırma grupları $125 \mathrm{GeV}$ civarında bozonik bir parçacık gözlemlendiğini açıklamışlardır[17,18]. Devamında yapılan deneylerde bu bozonik parçacığın Standart Model'de tahmin edilen Higgs bozonunun özelliklerine uyduğu görülmüştür [19].

Bundan sonraki süreçte ise Higgs bozonunun yaptığı bağlaşımların ölçülmesi Standard Model Higgs sektörünün test edilmesi açısından oldukça büyük önem arz etmektedir [20-27].

Özellikle Higgs özbağlaşımlarının deneylerce elde edilmesi sonucu Higgs potansiyelinin ve dolayısıyla Elektrozayıf Simetri Kırınımı'nın anlaşılması ve olası Yeni Fizik senaryoları hakkında bilgi edinilmesi için üzerinde durulması gereken bir konudur. Diğer taraftan Higgs bozonunun kendisi ile yaptığı üçlü bağlaşımın (ikili Higgs oluşumu) ölçülmesi şu an ki ve yeni teknoloji ile yapılabilecek çarpıştırıcılarla mümkün görünürken, maalesef dört Higgs bozonunun bağlaşması ile oluşan (üçlü Higgs oluşumu) süreçlerin ölçülmesi ancak çok daha ileriki çarpıştırıcılarda ele alınabilecektir [28].

Kütlesi $125 \mathrm{GeV}$ civarında olan bir Higgs'in bozunma süreçlerine ait gerçekleşme oranları dikkate alındığında çift Higgs üretiminde iki Higgs'in bozunma kanalları ve olasılıkları ise Tablo 1'de gösterilmiştir[29].

Tablo 1. Çift Higgs bozunum kanalları ve dallanma oranları.

\begin{tabular}{|c|c|}
\hline Bozunum Kanalı & Dallanma Oranı \\
\hline$h h \rightarrow b \bar{b} b \bar{b}$ & $\% 33$ \\
\hline$h h \rightarrow b \bar{b} W^{+} W^{-}$ & $\% 7.3$ \\
\hline$h h \rightarrow b \bar{b} \tau^{+} \tau^{-}$ & $\% 3.1$ \\
\hline$h h \rightarrow Z Z b \bar{b}$ & $\% 2.7$ \\
\hline$h h \rightarrow W^{+} W^{-} \tau^{+} \tau^{-}$ & $\% 1.1$ \\
\hline$h h \rightarrow Z Z W^{+} W^{-}$ & $\% 0.27$ \\
\hline$h h \rightarrow \gamma \gamma b \bar{b}$ & $\% 0.001$ \\
\hline$h h \rightarrow \gamma \gamma \gamma \gamma$ & \\
\hline
\end{tabular}

Tablo 1'de gösterilen bozunum kanalları arasında $h h \rightarrow b \bar{b} b \bar{b}$ ve $h h \rightarrow b \bar{b} W^{+} W^{-}$ kanalları en olası bozunum gibi görünmesine karşın LHC analizlerinde çok fazla arka alana sahip olduğundan çözümlenmesi bakımından zor süreçlerdir. Diğer yandan her ne kadar dallanma oranı olarak düşük olan $h h \rightarrow \gamma \gamma b \bar{b}$ kanalı QCD ve QED tekli Higgs üretiminden gelen arka alanlara $(Z h(\gamma \gamma)$ ve $h(\gamma \gamma) b \bar{b})$ sahip olsa da hem yukarıda bahsettiğimiz diğer bozunum kanallarına nazaran arka alanın daha az oluşu hem de 
hassasiyeti bakımından çift Higgs üretiminin analizi açısından tabloda görünen bozunum kanallarından en iyisidir [38,39].

Bu bölümün devamında Higgs'in üçlü özbağlaşımlarının bulunduğu ikili Higgs üretim süreçlerinin çarpıştırıcılardaki durumu ve ilgili Feynman diyagramları ele alınmıştır.

\subsection{Gluon füzyonu sürecinde Higgs çifti üretimi}

$\mathrm{Bu}$ süreç iki gluonun bir araya gelip, ağır kuark (genelde üst kuark) halkası yoluyla ortaya iki Higgs bozonu çıkarması olayıdır [30-33]. Ağaç seviyesinde oluşamayan ve Higgs çifti üretiminde en dominant süreçtir. Tesir kesitine en çok katkıyı veren üst ve alt kuarkların halka yapısında görüldüğü süreçler Şekil 1'de gösterilmiştir.
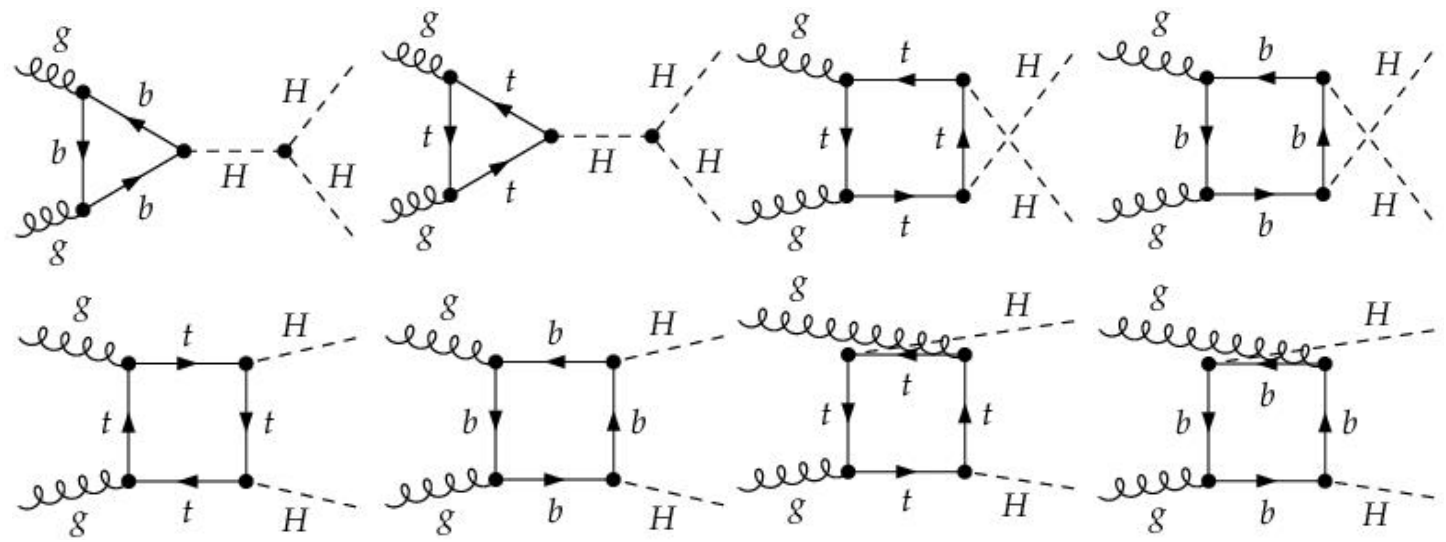

Şekil 1. Gluon füzyonu sürecinde olası Higgs çifti oluşum kanallarının Feynman diagramları

Şekil 1'de görüldüğü üzere gluon füzyonunda Higgs çifti oluşumu sadece halka düzeyinde ve iki farklı yapıda olur. Bunlardan biri iki gluonun üçgen şeklinde bir üst kuark halkası oluşturup üçgenin geriye kalan diğer köşesinden çıkan Higgs'in iki Higgs bozonuna bozunmasıdır ki, efektif özbağlaşımımızın katkı sunduğu süreç budur. Diğeri ise iki gluonun kare şeklinde bir üst kuark halkası oluşturup karenin geriye kalan diğer iki köşesinden çıkan birer Higgs bozonunu meydana getirmesidir. Gluon füzyonundan Higgs çifti oluşumu için partonik tesir kesitinin analitik ifadesi

$$
\hat{\sigma}(g g \rightarrow h h) \approx \int_{\hat{t}_{-}}^{\hat{t}_{+}} d \hat{t} \frac{1}{2^{2}} \frac{1}{8^{2}} \frac{1}{2 !} \frac{1}{16 \pi \hat{s}^{2}} \frac{2 \alpha_{S}^{2}}{(4 \pi)^{2}}\left|\frac{\Gamma_{h h h} v}{\hat{s}-m_{h}^{2}} F_{\Delta}+F_{\square}\right|^{2}
$$

şeklindedir[34]. Burada $F_{\Delta}$ ve $F_{\text {口 }}$ sirasıyla üçgen ve kare diyagramların halka fonksiyonları olup birbirleri ile zit işaretlidir. $\mathrm{Bu}$ durumu Higgs'in gluonlarla bağlaşımını içeren efektif Lagrangian teriminden görebiliriz[35].

$$
\begin{aligned}
L_{\text {eff }} & =\frac{\alpha_{s}}{12 \pi}(\log H) G_{\mu \nu}^{a} G^{a \mu \nu} \\
& =\frac{\alpha_{s}}{12 \pi}\left(\frac{h}{v}-\frac{h^{2}}{2 v^{2}}+\ldots\right) G_{\mu \nu}^{a} G^{a \mu \nu}
\end{aligned}
$$


Aynı zamanda (14) eşitliğinde de görüldügü gibi F teriminin önündeki katsayı Higgs'in üçlü bağlaşımı ile doğru orantılı olmasına karşın diyagramdaki sanal Higgs'in kütle karesi, s, ile ters orantılıdır [36]. Dolayısıyla tesir kesiti ifadesine göre kare diagramın katkısı üçgen diyagrama göre oldukça büyüktür. Sonuç olarak toplam tesir kesiti kare diyagramın sonucuna yaklaşmaktadır.

\section{2 ttHH sürecinde Higgs çifti üretimi}

Proton-proton çarpışması sonucu oluşan gluon ya da kuarkların biraraya gelmesi ile üst, anti üst kuark ve iki Higgs bozonu oluşması sürecidir. Tesir kesitine en çok katkıda bulunan süreçler Şekil 2'de gösterilmiştir.
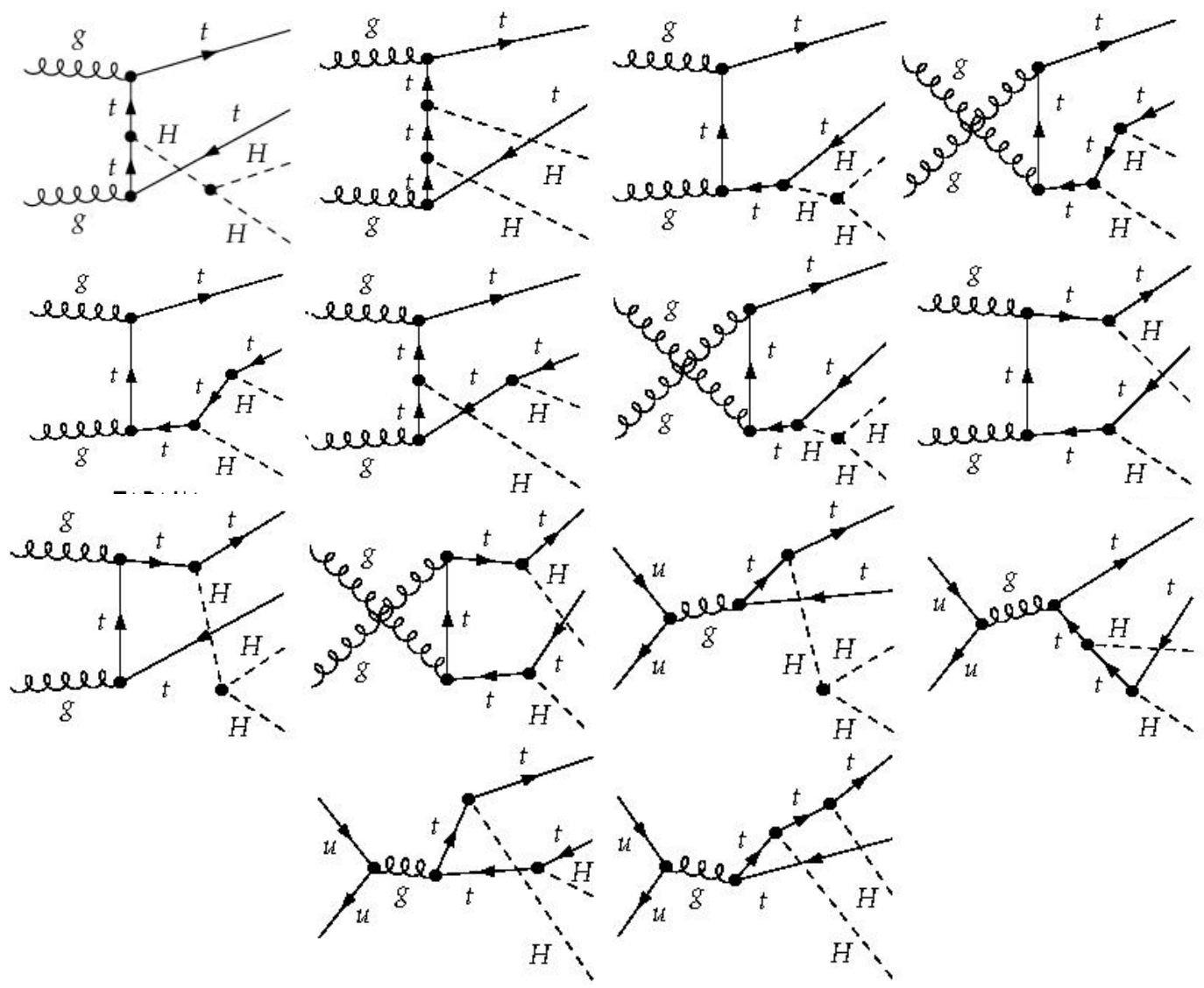

Şekil 2. ttHH sürecinde olası Higgs çifti oluşum kanallarının Feynman diagramları

\section{Yöntem}

$\mathrm{Bu}$ çalışmada, halka katkılı Higgs potansiyelinden yararlanarak elde edeceğimiz Higgs'in üçlü ve dörtlü öz bağlaşımlarını bulmak için literatürde de daha önce kullanılmış olan efektif potansiyel metodu kullanılmıştır. $\mathrm{Bu}$ metodun bir halka mertebesinde uygulanması ile efektif potansiyelin Higgs alanı cinsinden seri açılmış halini (16) eşitliğinde görüldüğü gibi yazabiliriz[37]. 


$$
\begin{aligned}
V_{\text {eff }} & =\frac{-\mu^{2}}{2}(v+h)^{2}+\frac{1}{4} \tilde{\lambda}(v+h)^{4} \\
& -\frac{N_{c}}{16 \pi^{2}} \frac{y_{t}^{4}}{2}(v+h)^{4}\left(\frac{h}{v}-\frac{h^{2}}{2 v^{2}}+\frac{h^{3}}{3 v^{3}}-\frac{h^{4}}{4 v^{4}}+\frac{h^{5}}{5 v^{5}}-\ldots\right)
\end{aligned}
$$

Bu efektif potasiyelden türetilen Higgs'in bir halka katkılı üçlü öz bağlaşımı ise

$$
\Gamma_{h h h}=\frac{3 m_{h}^{2}}{v}\left(1-\frac{N_{c}}{3 \pi^{2}} \frac{m_{t}^{4}}{v^{2} m_{h}^{2}}\right)
$$

şeklindedir.

Bu çalışmada kullanılan Higgs'in iki, üç ve dört halka katkılı üçlü öz bağlaşımları (9), (10) ve (11) eşitliklerindeki efektif Higgs potansiyelinden yukarıda gösterilen yöntemle türetilmiştir. (18), (19) ve (20) eşitliklerinde de anlaşılacağı gibi her bir katk1 kendisinden önce gelen halkaların katkılarını da içermektedir. Bu bağlaşımlar sırasıyla aşağıdaki gibidir.

$$
\begin{aligned}
\Gamma_{h h h}^{(2)}= & \frac{3 m_{h}^{2} e}{2 m_{W} \sin \left(\theta_{W}\right)}\left(1-\frac{m_{t}^{4} e^{2}}{4 m_{W}^{2} m_{h}^{2} \pi^{2} \sin ^{2}\left(\theta_{W}\right)}+\frac{7 m_{t}^{6} e^{4}}{256 m_{W}^{4} m_{h}^{2} \pi^{4} \sin ^{4}\left(\theta_{W}\right)}\right. \\
& \left.+\frac{m_{t}^{4} e^{2} g_{3}^{2}}{24 m_{W}^{2} m_{h}^{2} \pi^{4} \sin ^{2}\left(\theta_{W}\right)}\right) \\
\Gamma_{h h h}^{(3)} & =\frac{3 m_{h}^{2} e}{2 m_{W} \sin \left(\theta_{W}\right)}\left(1-\frac{m_{t}^{4} e^{2}}{4 m_{W}^{2} m_{h}^{2} \pi^{2} \sin ^{2}\left(\theta_{W}\right)}+\frac{7 m_{t}^{6} e^{4}}{256 m_{W}^{4} m_{h}^{2} \pi^{4} \sin ^{4}\left(\theta_{W}\right)}\right. \\
& +\frac{m_{t}^{4} e^{2} g_{3}^{2}}{24 m_{W}^{2} m_{h}^{2} \pi^{4} \sin ^{2}\left(\theta_{W}\right)}-\frac{367 m_{t}^{8} e^{6}}{8192 m_{W}^{6} m_{h}^{2} \pi^{6} \sin ^{6}\left(\theta_{W}\right)}+\frac{5 m_{t}^{6} e^{4} g_{3}^{2}}{96 m_{W}^{4} m_{h}^{2} \pi^{6} \sin ^{4}\left(\theta_{W}\right)} \\
& \left.+\frac{53 m_{t}^{4} e^{2} g_{3}^{4}}{768 m_{W}^{2} m_{h}^{2} \pi^{6} \sin ^{2}\left(\theta_{W}\right)}\right) \\
\Gamma_{h h h}^{(4)} & =\frac{3 m_{h}^{2} e}{2 m_{W} \sin ^{2}\left(\theta_{W}\right)}\left(1-\frac{7 m_{t}^{6} e^{4}}{4 m_{W}^{2} m_{h}^{2} \pi^{2} \sin ^{2}\left(\theta_{W}\right)}+\frac{m_{t}^{4} e^{2}}{256 m_{W}^{4} m_{h}^{2} \pi^{4} \sin ^{4}\left(\theta_{W}\right)}\right. \\
& +\frac{m_{t}^{4} e^{2} g_{3}^{2}}{24 m_{W}^{2} m_{h}^{2} \pi^{4} \sin ^{2}\left(\theta_{W}\right)}-\frac{3677 m_{t}^{8} e^{6}}{8192 m_{W}^{6} m_{h}^{2} \pi^{6} \sin ^{6}\left(\theta_{W}\right)}+\frac{5 m_{t}^{6} e^{4} g_{3}^{2}}{96 m_{W}^{4} m_{h}^{2} \pi^{6} \sin ^{4}\left(\theta_{W}\right)} \\
& \left.+\frac{53 m_{t}^{4} e^{2} g_{3}^{4}}{768 m_{W}^{2} m_{h}^{2} \pi^{6} \sin ^{2}\left(\theta_{W}\right)}+\frac{1609 m_{t}^{4} e^{2} g_{3}^{6}}{49152 m_{W}^{2} m_{h}^{2} \pi^{8} \sin ^{2}\left(\theta_{W}\right)}\right)
\end{aligned}
$$

Bu bağlaşımlar kullanılarak FeynArts paket programı [38] için yeni bir model dosyası oluşturulmuştur. Büyük Hadron Çarpıştırıcısı (LHC, HL-LHC ve FCC) ve Uluslararası Doğrusal Çarpıştırıcı'daki (elektron-pozitron ve foton-foton çarpıştırıcıları) bu bağlaşımları içeren Higgs üretim süreçlerinin bir önceki bölümde gösterilen Feynmann diyagramları FeynArts vasıtasıyla çizdirilmiş matris elemanlarının (genliklerinin) analitik hesaplanması FormCalc [39] programı kullanılarak, varsa halka integrallerinin 
çözümü LoopTools [40] yardımı ile yapılmış ve ilgili süreç için tesir kesiti hesaplamamıza yarayan Fortran kodları elde edilmiştir.

\section{Sonuçlar ve tartışma}

$\mathrm{Bu}$ bölümde elde edilen sonuçlar grafikler ve tablolar yardımıyla gösterilmiştir. Her bir grafikte kırmızı renk ağaç seviyesindeki Higgs öz bağlaşımlarının bulunduğu süreçleri, mavi renk 1-halka seviyesinde düzeltilmiş Higgs öz bağlaşımlarının bulunduğu süreçleri, turuncu renk 2-halka seviyesinde düzeltilmiş Higgs öz bağlaşımlarının bulunduğu süreçleri, mor renk 3-halka seviyesinde düzeltilmiş Higgs öz bağlaşımlarının bulunduğu süreçleri ve yeşil renk 4-halka seviyesinde düzeltilmiş Higgs öz bağlaşımlarının bulunduğu süreçleri göstermektedir. Her alt bölümde grafiklerin ardından Büyük Hadron Çarpıştırıcısına ait çarpışma enerjilerine dönük tahminleri içeren tablolar verilmiştir.

\subsection{Gluon füzyonu sürecinde Higgs çifti üretimi}

Bu süreç için Şekil 1'de gösterilen kanallar her bir halka katkısı için hesaplanmış ve bu süreç için toplam tesir kesiti bulunmuştur. Şekil 3'de kütle merkezi çarpışma enerjisine karş1lık Higgs çifti oluşum tesir kesiti grafiği gösterilmiştir.

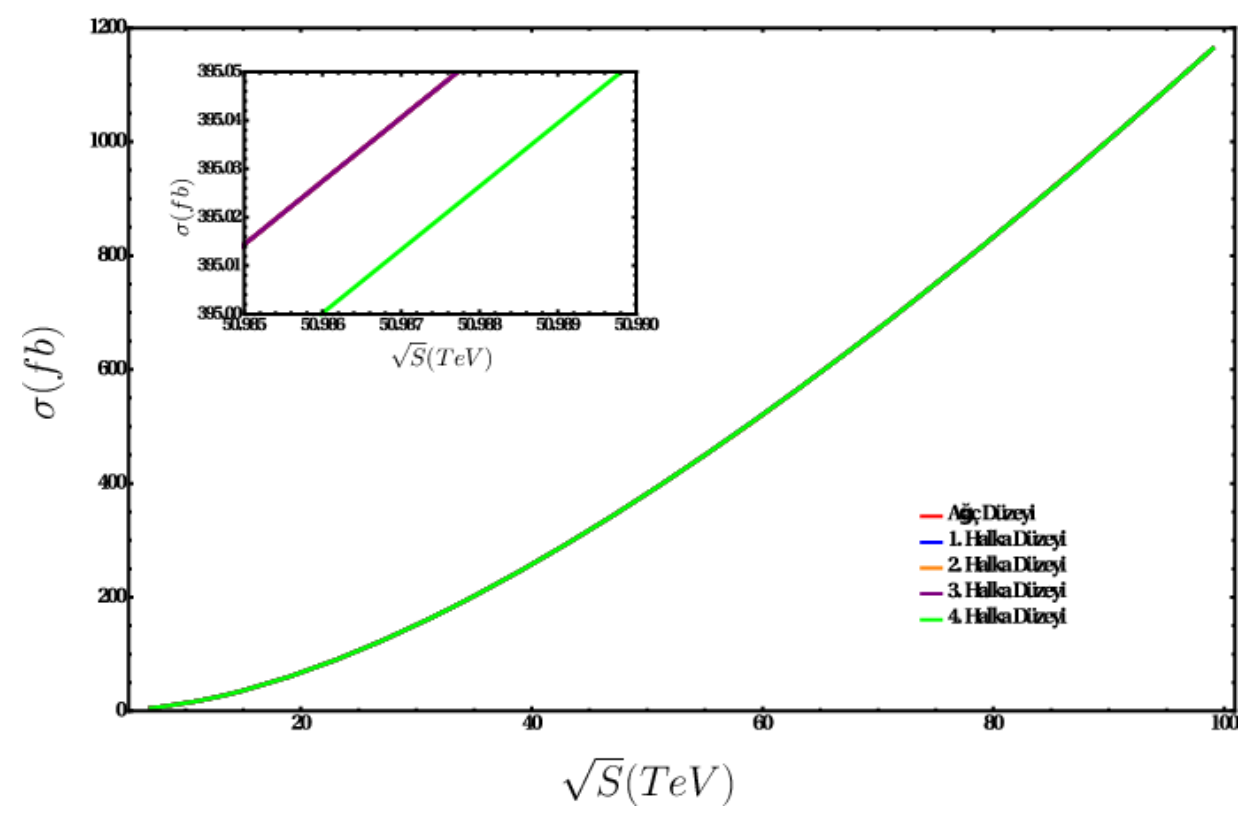

Şekil 3. Gluon füzyonu sürecinde çarpışma enerjisine karşılık Higgs çifti oluşum tesir kesiti grafiği.

Grafikte görüldüğü gibi bu süreçte Higgs'in özbağlaşımına gelen halka etkilerini ağaç seviyesinden ayırmak neredeyse imkansızdır. Bunun sebebi dördüncü bölümde anlatılan üçgen ve kare diyagramların katkı oranları arasındaki durumdur. Bu durum Şekil 4'te daha net gözlemlenebilir. 


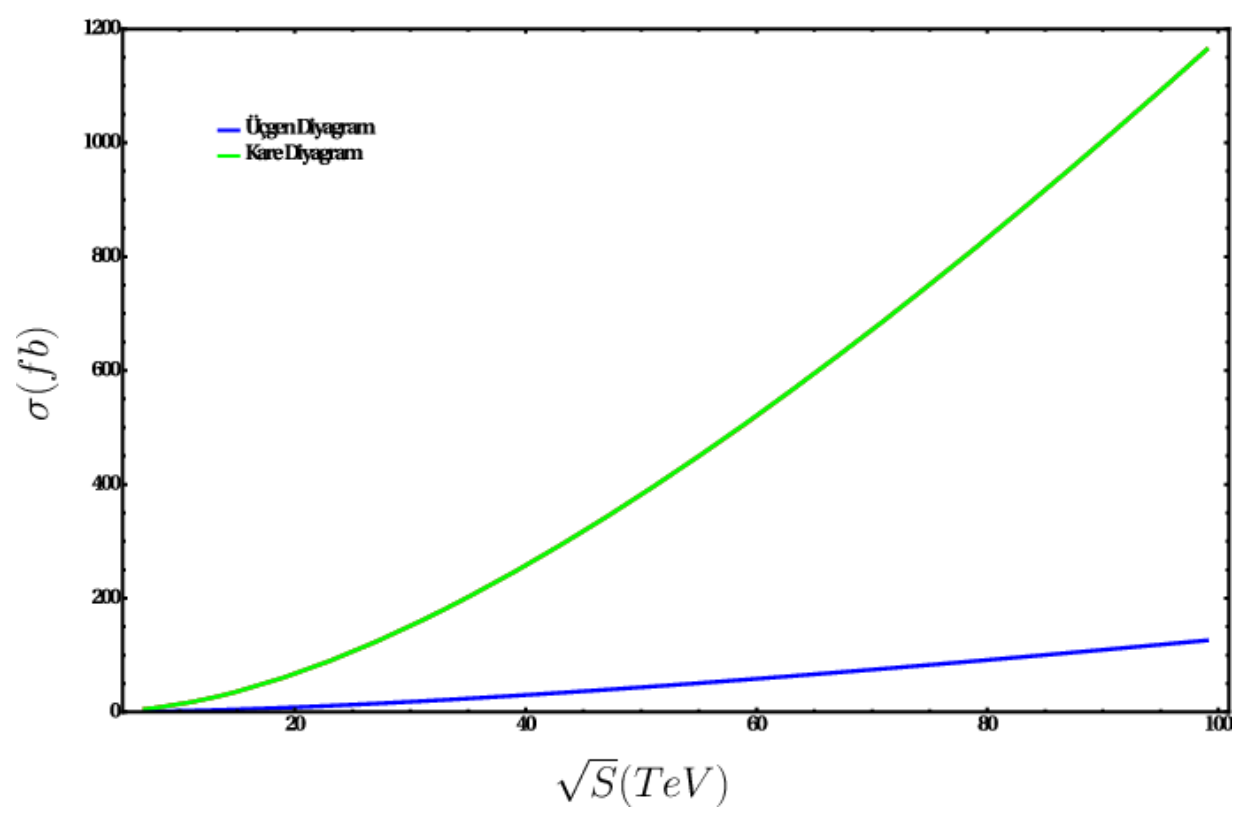

Şekil 4. Gluon füzyonu sürecinde üçgen, kare ve tüm diyagramlar için (ağaç seviyesinde üçlü Higgs bağlaşımı kullanılarak elde edilen) çarpışma enerjisine karşılık Higgs çifti oluşum tesir kesiti grafiği.

Öte yandan üçgen diyagram için tesir kesitinin Higgs'in efektif öz bağlaşımları ile ilişkisi Şekil 5'te gösterilmiştir. Buna göre üçgen diyagramların tesir kesiti katkısı için bir, iki, üç ve dört halka katkılı Higgs'in efektif özbağlaşımları arasında bir fark görünmemektedir. Fakat Şekil 6’ten görüleceği gibi Ağaç mertebesindeki üçlü Higgs bağlaşımı ile aralarında yüzde 18'e varan farklar mevcuttur. Bu farkın toplam tesir kesitinde anlaşılması daha önce anlatılan nedenden dolayı mümkün değildir. Dolayısıyla Higgs'in üçlü bağlaşımına gelen halka katkılarının anlaşılması açısından gluon füzyonu yararlı bir kanal değildir. Bunun iyi tarafı ise yüksek halka katkılarından bir belirsizliğin gelmeyecek oluşudur. Üçgen ve kare diyagramlarının halka fonksiyonlarının zit işarete sahip olmasından dolayı ağır Standart ötesi ağır parçacıkların öz bağlaşıma yapacağı negatif (pozitif) katkılar ile toplam tesir kesitinde pozitif (negatif) değişimler meydana getirme potansiyeline sahiptir. Bu yüzden yeni fizik teorileri için LHC'de bakılması gereken en önemli kanal olma özelliğini korumaktadir. 


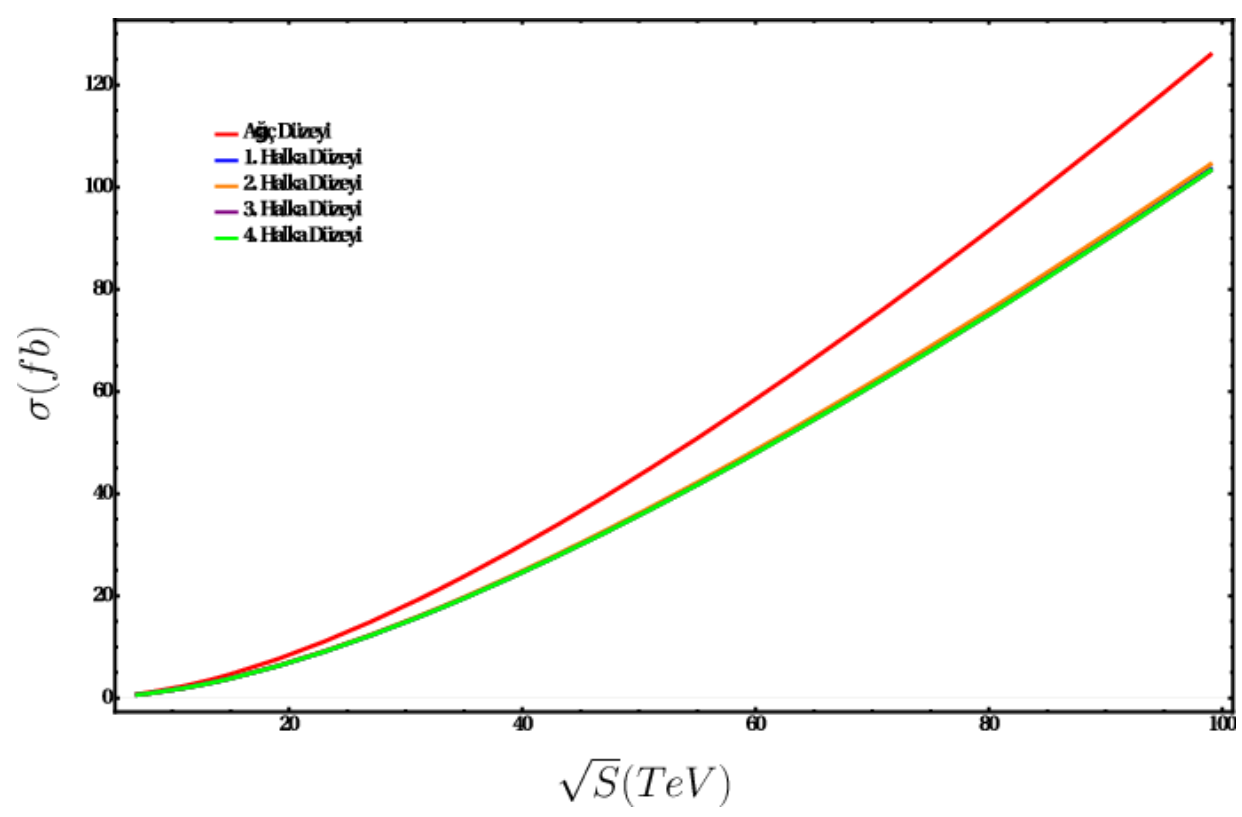

Şekil 5. Gluon füzyonu sürecinde üçgen diyagramlar için çarpışma enerjisine karşılık Higgs çifti oluşum tesir kesiti grafiği

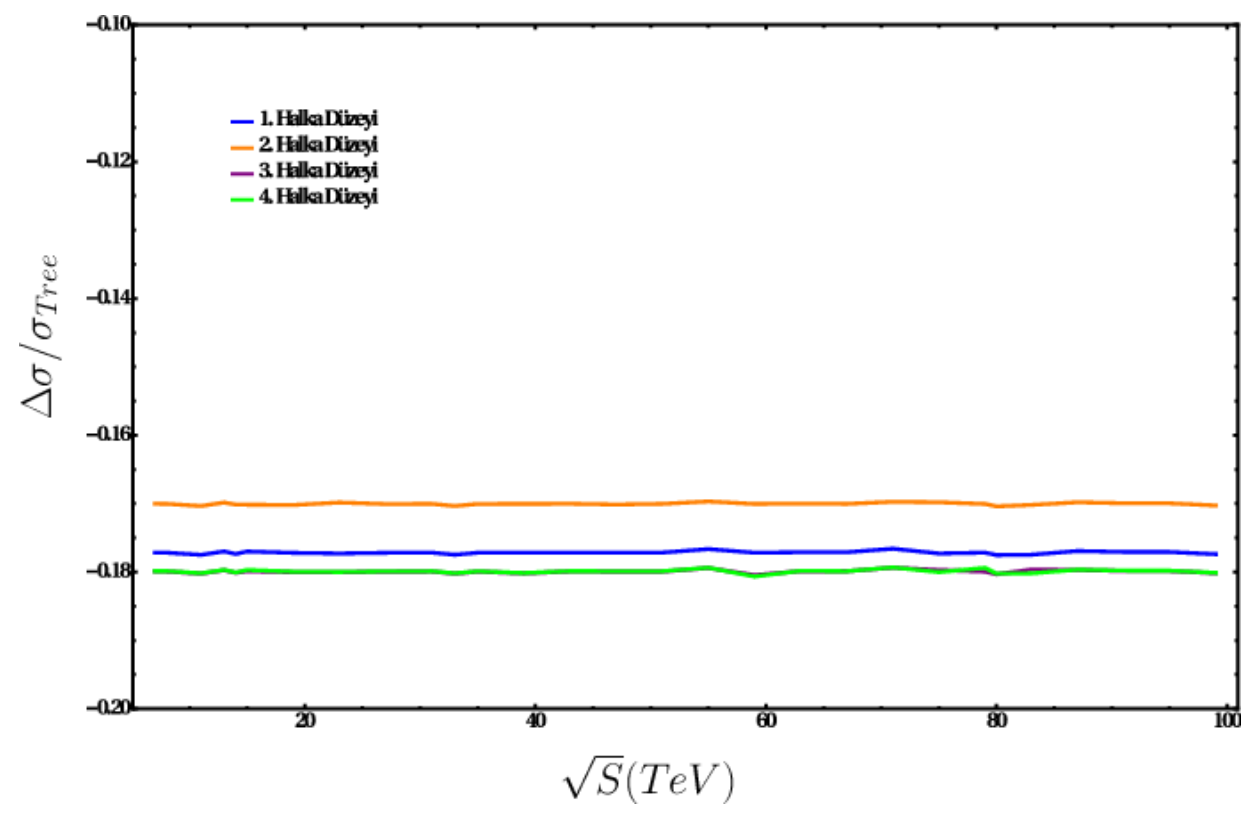

Şekil 6. Gluon füzyonu sürecinde üçgen diyagramlar için çarpışma enerjisine karşılık, her halka seviyesi için Higgs çifti oluşum tesir kesitinin ağaç seviyesi tesir kesitine oranı grafiği

\section{2 ttHH sürecinde Higgs çifti üretimi}

Bu süreç için en çok katkının geldiği Şekil 2'de gösterilen gluon ve yukarı kuarkın oluşturduğu kanallar her bir halka katkısı için hesaplanmış ve toplam tesir tesiti bulunmuştur. Şekil 7'de kütle merkezi çarpışma enerjisine karşılık Higgs çifti oluşum tesir kesiti grafiği gösterilmiştir. 


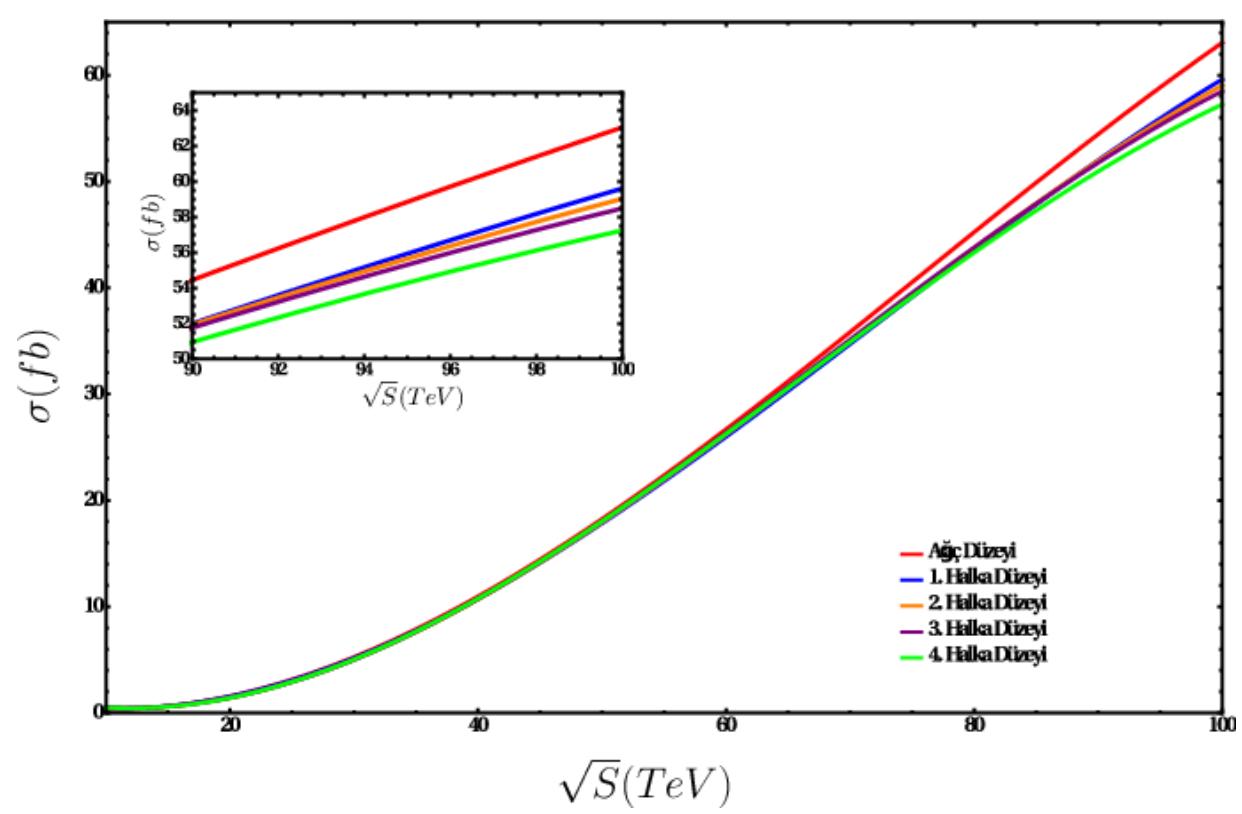

Şekil 7. ttHH sürecinde çarpışma enerjisine karş1lık Higgs çifti oluşum tesir kesiti grafiği

Şekil 7'den anlaşılacağı gibi bu süreçte halka etkilerinin ağaç seviyesinden en fazla ayrılan bölge çarpışma enerjisinin $100 \mathrm{TeV}$ (FCC) olacağı bölgedir. Diğer taraftan Şekil 8 'den bu süreç için ağaç ile halka seviyeleri arasındaki farkın en fazla yaklaşık yüzde 8 olacağı anlaşılmaktadır. Ayrıca bu çarpışma enerjisinde dört halka katkılı süreç diğer halka katkılarından kabaca yüzde üç ayrılmaktadır.

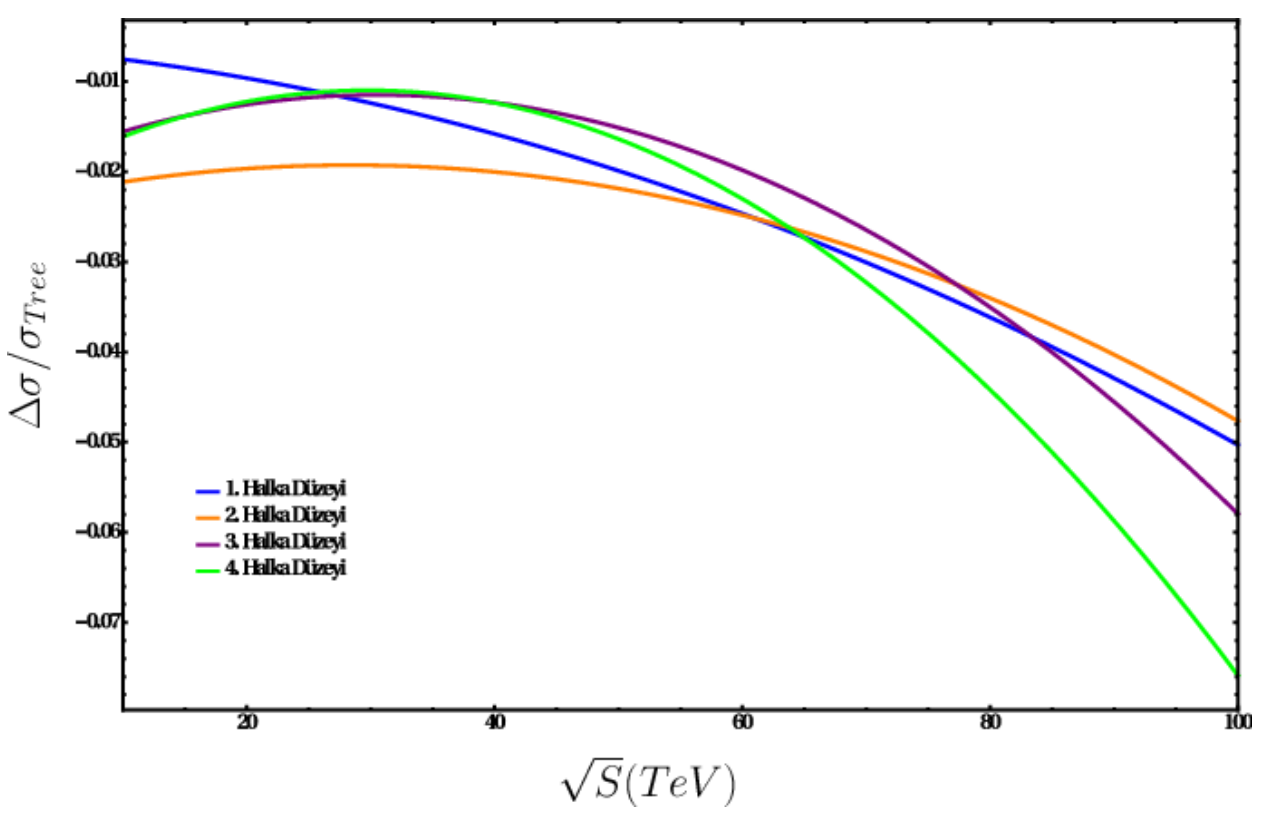

Şekil 8. ttHH sürecinde çarpışma enerjisine karşılık her halka seviyesi için Higgs çifti oluşum tesir kesitinin ağaç seviyesi tesir kesitine oranı grafiği

Tablo 2'de Şekil 7'deki grafikte gösterilen tesir kesitleri Büyük Hadron Çarpıştırıcısı ve ileride geliştirilecek olan HL-LHC ve FCC çarpıştırıcılarındaki olası çarpışma enerjileri için ağaç seviyesi ve halka seviyeleri için gösterilmiştir. Tablo 3 'de bu enerjilerde çift 
Higgs bozunum kanalları için tesir kesitleri gösterilmiş olup, Tablo $4^{6}$ te bu kanallar için bozunum sayıları gösterilmiştir.

Tablo 2. ttHH sürecinde LHC'deki çarpışma enerjileri için tesir kesitleri.

\begin{tabular}{|c|c|c|c|c|c|}
\hline $\begin{array}{c}\sqrt{s} \\
(\mathrm{TeV})\end{array}$ & $\begin{array}{c}\sigma_{\text {Tree }} \\
(\mathrm{fb})\end{array}$ & $\begin{array}{c}\sigma_{1-\text { Loop }} \\
(\mathrm{fb})\end{array}$ & $\begin{array}{c}\sigma_{2-\text { Loop }} \\
(\mathrm{fb})\end{array}$ & $\begin{array}{c}\sigma_{3-\text { Loop }} \\
(\mathrm{fb})\end{array}$ & $\begin{array}{c}\sigma_{4-\text { Loop }} \\
(\mathrm{fb})\end{array}$ \\
\hline $\mathbf{1 4}$ & 0.528 & 0.544 & 0.511 & 0.542 & 0.513 \\
\hline $\mathbf{3 3}$ & 6.769 & $\mathbf{6 . 6 4 3}$ & 6.518 & $\mathbf{6 . 5 2 1}$ & 6.554 \\
\hline $\mathbf{8 0}$ & 45.235 & $\mathbf{4 3 . 5 4 2}$ & 43.761 & $\mathbf{4 3 . 7 9 2}$ & 43.314 \\
\hline $\mathbf{1 0 0}$ & 63.054 & $\mathbf{5 9 . 6 1 4}$ & 59.033 & $\mathbf{5 8 . 4 9 3}$ & 57.244 \\
\hline
\end{tabular}

Tablo 3. ttHH sürecinde LHC'deki enerjilere dönük çift Higgs bozunum kanalları tesir kesitleri.

\begin{tabular}{|c|c|c|c|c|c|c|}
\hline \multirow{2}{*}{$\begin{array}{c}\text { Bozunum } \\
\text { Kanalı }\end{array}$} & $\begin{array}{c}\sqrt{S} \\
(\mathrm{TeV})\end{array}$ & $\sigma_{\text {Tree }} \cdot B R$ & $\sigma_{1-\text { Loop }} . B R$ & $\sigma_{2-\text { Loop }} . B R$ & $\sigma_{3-\text { Loop }} . B R$ & $\sigma_{4-\text { Loop }} . B R$ \\
\hline \multirow{4}{*}{$h h \rightarrow b \bar{b} b \bar{b}$} & 14 & $\mathbf{0 . 1 7 4}$ & 0.179 & $\mathbf{0 . 1 6 8}$ & 0.168 & $\mathbf{0 . 1 6 9}$ \\
\cline { 2 - 7 } & 33 & $\mathbf{2 . 2 3 3}$ & 2.192 & $\mathbf{2 . 1 5 1}$ & 2.152 & $\mathbf{2 . 1 6 3}$ \\
\cline { 2 - 7 } & 80 & $\mathbf{1 4 . 9 2 7}$ & 14.368 & $\mathbf{1 4 . 4 4 1}$ & 14.451 & $\mathbf{1 4 . 2 9 3}$ \\
\cline { 2 - 7 } & 100 & $\mathbf{2 0 . 8 0}$ & 19.672 & $\mathbf{1 9 . 4 8 1}$ & 19.302 & $\mathbf{1 8 . 8 9 0}$ \\
\hline \multirow{3}{*}{$h h \rightarrow b \bar{b} W^{+} W$} & 14 & $\mathbf{0 . 1 3 2}$ & 0.126 & $\mathbf{0 . 1 2 7}$ & 0.127 & $\mathbf{0 . 1 2 8}$ \\
\cline { 2 - 7 } & 33 & $\mathbf{1 . 6 9 2}$ & 1.660 & $\mathbf{1 . 6 2 9}$ & 1.630 & $\mathbf{1 . 6 3 8}$ \\
\cline { 2 - 7 } & 100 & $\mathbf{1 1 . 3 0 8}$ & 10.885 & $\mathbf{1 0 . 9 4 0}$ & 10.948 & $\mathbf{1 0 . 8 2 8}$ \\
\hline \multirow{3}{*}{$h h \rightarrow \gamma \gamma b \bar{b}$} & 14 & $\mathbf{0 . 0 0 1 4}$ & 0.0014 & $\mathbf{0 . 0 0 1 3}$ & 0.0014 & $\mathbf{0 . 0 0 1 3}$ \\
\cline { 2 - 7 } & 33 & $\mathbf{0 . 0 1 8}$ & 0.017 & $\mathbf{0 . 0 1 7}$ & 0.017 & $\mathbf{0 . 0 1 7}$ \\
\cline { 2 - 7 } & 80 & $\mathbf{0 . 1 2 2}$ & 0.117 & $\mathbf{0 . 1 1 8}$ & 0.118 & $\mathbf{0 . 1 1 7}$ \\
\cline { 2 - 7 } & 100 & $\mathbf{0 . 1 7 0}$ & 0.161 & $\mathbf{0 . 1 5 9}$ & 0.157 & $\mathbf{0 . 1 5 4}$ \\
\hline
\end{tabular}


Tablo 4. ttHH sürecinde LHC'deki enerjilere dönük çift Higgs bozunum sayıları.

\begin{tabular}{|c|c|c|c|c|}
\hline Çarpıştırıcı & $\begin{array}{l}\text { Bozunum } \\
\text { Kanalı }\end{array}$ & $\begin{array}{c}\text { Ağaç Düzeyi } \\
\text { Bozunum Sayısı }\end{array}$ & $\begin{array}{l}\text { 4-Halka Düzeyi } \\
\text { Bozunum Sayısı }\end{array}$ & \% Fark \\
\hline \multirow{2}{*}{$\begin{array}{c}\text { LHC } \\
14 \mathrm{TeV} \\
300 \mathrm{fb}^{-1}\end{array}$} & $h h \rightarrow b \bar{b} b \bar{b}$ & 52 & 51 & -1.9 \\
\hline & $h h \rightarrow b \bar{b} W^{+} W^{-}$ & 40 & 39 & -2.5 \\
\hline \multirow{3}{*}{$\begin{array}{c}\text { HL-LHC } \\
14 \mathrm{TeV} \\
3000 \mathrm{fb}^{-1}\end{array}$} & $h h \rightarrow b \bar{b} b \bar{b}$ & 522 & 507 & -2.8 \\
\hline & $h h \rightarrow b \bar{b} W^{+} W^{-}$ & 396 & 384 & -3.0 \\
\hline & $h h \rightarrow \gamma \gamma b \bar{b}$ & 4 & 4 & 0 \\
\hline \multirow{3}{*}{$\begin{array}{c}\text { FCC } \\
33 \mathrm{TeV} \\
\mathbf{3 0 0} \mathbf{f b}^{-1}\end{array}$} & $h h \rightarrow b \bar{b} b \bar{b}$ & 669 & 648 & -3.1 \\
\hline & $h h \rightarrow b \bar{b} W^{+} W^{-}$ & 507 & 489 & -3.5 \\
\hline & $h h \rightarrow \gamma \gamma b \bar{b}$ & 5 & 5 & 0 \\
\hline \multirow{3}{*}{$\begin{array}{c}\text { FCC } \\
33 \mathrm{TeV}^{-1} \\
3000 \mathbf{f b}^{-1}\end{array}$} & $h h \rightarrow b \bar{b} b \bar{b}$ & 6699 & 6489 & -3.1 \\
\hline & $h h \rightarrow b \bar{b} W^{+} W^{-}$ & 5076 & 4914 & -3.1 \\
\hline & $h h \rightarrow \gamma \gamma b \bar{b}$ & 54 & 51 & -5.5 \\
\hline \multirow{3}{*}{$\begin{array}{c}\text { FCC } \\
80 \mathrm{TeV}^{-1} \\
3000 \mathbf{f b}^{-1}\end{array}$} & $h h \rightarrow b \bar{b} b \bar{b}$ & 44781 & 42879 & -4.2 \\
\hline & $h h \rightarrow b \bar{b} W^{+} W^{-}$ & 33924 & 32484 & -4.2 \\
\hline & $h h \rightarrow \gamma \gamma b \bar{b}$ & 366 & 351 & -4.2 \\
\hline \multirow{3}{*}{$\begin{array}{c}\text { FCC } \\
100 \mathrm{TeV} \\
3000 \mathrm{fb}^{-1}\end{array}$} & $h h \rightarrow b \bar{b} b \bar{b}$ & 62400 & 56670 & -9.1 \\
\hline & $h h \rightarrow b \bar{b} W^{+} W^{-}$ & 47289 & 42933 & -9.2 \\
\hline & $h h \rightarrow \gamma \gamma b \bar{b}$ & 510 & 462 & -9.4 \\
\hline
\end{tabular}

Büyük Hadron Çarpıştırıcısı'ndaki en önemli kanal olan gluon füzyonunda halka etkilerinin gözlemlenmesi için uygun olmayan bir kanal olmasına rağmen, ekstra bir belirsizliğin gelmemesinden ötürü BHÇ’daki çarpışma enerjilerinde olası yeni fizik teorilerinin gözlemlenebileceği en önemli kanal olma özelliğini korumaktadır. FCC gibi daha çok yüksek çarpışma enerjilerinde önemli süreçlerden biri haline gelen ttHH kanalında ise bahsettiğimiz etkiler ancak 80-100 TeV aralığındaki çarpışma enerjilerinde gözlemlenebilir olmaktadır. Ağaç seviyesine göre bu çarpışma enerjilerinde yüzde 4 ile yüzde 9 arasında tesir kesiti farkı ortaya çıkmaktadır. Bununla birlikte $100 \mathrm{TeV}$ çarpışma enerjisinde bir halka katkılı üçlü Higgs öz bağlaşımı içeren sürece göre yüzde 3'lük bir fark vardır. Sonuç olarak tesir kesitindeki belirsizlik yüksek halka mertebesinde biraz daha giderilmiştir. 
Son olarak bu iki kanal dışında diğer önemli bir kanal vektör bozon füzyonudur ( $p p \rightarrow h h q \bar{q})$. Bu kanal şu anki BHÇ enerji seviyesi olan 14 TeV'de Higgs'in vektör bozonlar ile bağlaşımına ( $V V h$ ve $V V h h$ ) oldukça duyarlıdır[41]. Diğer yandan Higgs'in üçlüü bağlaşımına duyarlılığı bu enerji seviyesinde düşüktür. Dolayısıyla 14 $\mathrm{TeV}$ mertebesinde bu kanala ait halka katkılarının bu çalışmada gözlemlenen gluon füzyonu ve ttHH kanallarından daha düşük olması beklenir. Öte yandan FCC enerji seviyesi olan 100 TeV'e yaklaştıkça vektör bozon füzyonu ile ttHH kanalının tesir kesitleri büyüklük olarak birbirine yaklaşır. Bundan dolayı çarpıştırıcı enerjisinin artmasıyla vektör bozon füzyonu kanalındaki halka katkılarının ttHH kanalı ile aynı seviyede olması beklenir.

\section{Kaynaklar}

[1] Papaefstathiou, A., Yang, L. L. and Zurita, J., Higgs boson pair production at the LHC in the $\$ b \backslash$ bar $\{b\} W^{\wedge}+\mathrm{W}^{\wedge}-\$$ channel, Phys. Rev. D, 87, 011301, (2013); Gupta, R. S., Rzehak, H. and Wells, J. D., How well do we need to measure the Higgs boson mass and self-coupling?, Phys. Rev. D, 88, 055024, (2013).

[2] Baglio, J., Djouadi, A., Grober, R., Muhlleitner M. M., Quevillon J. and Spira M., "The measurement of the Higgs self-coupling at the LHC: theoretical status", JHEP, 1304, 151, (2013).

[3] Dicus, D.A., Kao, C . and Willenbrock, S. S. D., Higgs Boson Pair Production From Gluon Fusion, Phys. Lett. B, 203, 457, (1988).

[4] Dawson, S., Dittmaier ,S. and Spira, M., Neutral Higgs boson pair production at hadron colliders: QCD corrections, Phys. Rev. D, 58, 115012 (1998); Djouadi, A., Kilian, W., Muhlleitner, M. and Zerwas, P. M., Production of neutral Higgs boson pairs at LHC, Eur. Phys. J. C, 10, 45, (1999).

[5] Baur, U., Plehn, T. and Rainwater, D. L., Probing the Higgs selfcoupling at hadron colliders using rare decays, Phys. Rev. D, 69, 053004, (2004).

[6] Fujii, K., Physics at the ILC with focus mostly on Higgs physics, arXiv:1305.1692 [hep-ex], (2013).

[7] Plehn, T. and Rauch, M., The quartic higgs coupling at hadron colliders, Phys. Rev. D, 72, 053008, (2005).

[8] Weinberg, S., A Model of Leptons, Phys. Rev. Lett., 19, 1264, (1967).

[9] Salam, A., Nobel Symposium No.8, ed. N.Svartholm (Almqvis and Wiksell, Stockholm), (1969).

[10] Glashow, S. L., Partial Symmetries of Weak Interactions, Nucl. Phys., 22, 579, (1961).

[11] Nambu, Y., Axial vector current conservation in weak interactions, Phys. Rev. Lett., 4,380-382, (1960).

[12] Coleman, S. and Weinberg, E., Radiative corrections as the origin of spontaneous symmetry breaking, Phys.Rev.D, vol.7,pp.1888-1910, (1973).

[13] Ford, C., Jack, I., Jones, D. R. T., The Standard model effective potential at two loops, Nucl.Phys. B, 387, 373, (1992).

[14] Ford, C., Jones, D. R. T. , The Effective potential and the differential equations method for Feynman integrals, Phys. Lett. B, 274, 409, (1992).

[15] Martin, S. P., Three-loop Standard Model effective potential at leading order in strong and top Yukawa couplings, Phys. Rev. D, 89, 013003, (2014).

[16] Martin, S. P. ,Four-loop Standard Model effective potential at leading order in QCD, Phys. Rev. D, 92, 5, 054029, (2015). 
[17] The ATLAS Collaboration, Observation of a new particle in the search for the Standard Model Higgs boson with the ATLAS detector at the LHC, Phys. Lett. B,716,1-29, (2012).

[18] The CMS Collaboration, Observation of a new boson at a mass of $125 \mathrm{GeV}$ with the CMS experiment at the LHC, Phys. Lett. B, 716,30-61, (2012).

[19] The ATLAS Collaboration, Measurements of Higgs boson production and couplings in diboson final states with the ATLAS detector at the LHC, Phys. Lett. B, 726, 88, (2013).

[20] Giardino, P. P., Kannike, K., Raidal, M., Strumia, A., Reconstructing Higgs boson properties from the LHC and Tevatron data, JHEP, 1206, 117, (2012).

[21] Azatov, A., Contino, R., Del, Re D., Galloway, J., Grassi, M., et al., Determining Higgs couplings with a model-independent analysis of h->gamma gamma, JHEP, 1206,134, (2012).

[22] Klute, M., Lafaye, R., Plehn, T., Rauch, M., Zerwas, D., Measuring Higgs Couplings from LHC Data, Phys.Rev.Lett., 109,101801, (2012).

[23] Carmi, D., Falkowski, A., Kuik, E., Volansky, T., Zupan, J., Higgs After the Discovery: A Status Report, JHEP, 1210,196, (2012).

[24] Djouadi, A., Precision Higgs coupling measurements at the LHC through ratios of production cross sections, The European Physical Journal C , 73:2498, (2013).

[25] Cacciapaglia G., Deandrea A., La Rochelle G. D., Flament J. B., Higgs couplings beyond the Standard Model, JHEP ,03,029, (2013).

[26] Masso, E., Sanz, V., Limits on Anomalous Couplings of the Higgs to Electroweak Gauge Bosons from LEP and LHC, Phys. Rev. D, 87, 033001, (2013).

[27] Belanger, G., Dumont, B., Ellwanger, U., Gunion, J., Kraml, S., Higgs Couplings at the End of 2012, JHEP ,02,053, (2013).

[28] Dolan, M. J., Englert, C., Spannowsky, M., Higgs self-coupling measurements at the LHC, JHEP, 1210,112, (2012).

[29] Styles, N., Summary of Run 1 Searches and HL-LHC Prospects studies, Higgs Pair Production at Colliders Workshop, Mainz,(2015).

[30] Eboli, O., Marques, G., Novaes, S. and Natale, A., Twin Higgs-boson production, Phys. Lett. B, 197, 269, (1987).

[31] Glover, E. and Bij, J. vd., Higgs boson pair production via gluon fusion, Nucl. Phys. B, 309, 282, (1988).

[32] Dicus, D., Kao, C. and Willenbrock, S., Higgs Bboson pair production from gluon fusion, Phys. Lett. B, 203, 457, (1988).

[33] Plehn, T., Spira, M. and Zerwas, P.M., Pair production of neutral Higgs particles in gluon-gluon collisions, Nucl. Phys. B, 479, 46, (1996).

[34] Glover, E. W. N. and Bij, J. J. v.d., Higgs Pair Production via Gluon Fusion , Nucl. Phys. B, 309, 282, (1988).

[35] Haba, N., Kaneta, K., Mimura, Y. and Tsedenbaljir, E., Higgs Pair Production at the LHC and ILC from general potential, Phys. Rev. D, 89, 015018 (2014).

[36] Plehn, T., Spira, M. and Zerwas, P. M., Pair Production of Nautral Higgs Particles In Glulon-Gluon Collisions, Nucl. Phys. B , 479, 46 (1996).

[37] Kanemura, S., Kiyoura ,S.,,Okada ,Y., Senaha, E., and Yuan, C.-P.,New physics effect on the Higgs self-coupling, Phys. Lett. B, 558, 157-164,(2003); Kanemura, S., Okada, Y., Senaha, E., and Yuan, C.-P.,Higgs coupling constants as a probe of new physics, Phys. Rev. D, 70, 115002, (2004). 
[38] Hahn, T., Generating Feynman Diagrams and Amplitudes with FeynArts 3, Comp. Phys. Commun., 140, 418, (2001).

[39] Hahn, T., Excursions into FeynArts and FormCalc, Nucl.Phys.Proc.Suppl., 160, 101-105, (2006).

[40] Hahn, T., Automatic Loop Calculations with FeynArts, FormCalc, and LoopTools, Nucl. Phys. Proc. Suppl., 89, 231, (2000).

[41] Bishara F., Contino R. and Rojo J., Higgs pair production in vector-boson fusion at the LHC and beyond, Eur. Phys. J., C77, 7, 481, (2017). 